\title{
Micro Hydro Power Assessment in Lower Mahi Basin
}

\author{
Himanshu Bavishi ${ }^{1}$ Bhagat N.K ${ }^{2}$ \\ ${ }^{1}$ U.G Student, Department of Civil Engineering, Indus University, Ahmedabad, India \\ ${ }^{2}$ Assistant Professor, Department of Civil Engineering, Indus University, Ahmedabad, India
}

\begin{abstract}
Faced with the twin threats of human-induced climate change and concerns over security of supply, India must find new and sustainable sources of energy to fuel the ever-increasing demand. India generates $20 \%$ electricity form hydro power. Micro-hydro generation as a key contributor to future energy supply. It is one of a number of different micro hydro-generation options. Although its true potential has yet to be realised. This study estimates the potential for micro-hydropower generation in the Lower Mahi Basin.HES-RAS software isusedfor simulating the discharge and water head for calculation for power generation. Micro Hydro Power plant provide electricity which is pollution free by means of reducing in environmental hazardous material. Micro Hydro Power also provide water for irrigation, residential, commercial and raw water for water treatment plant. This research only focusses on the theoretical approach of Micro Hydro Power assessment in the study area.
\end{abstract}

Keyword: HAC-RAS, Lower Mahi Basin, Micro hydro power

\section{Introduction}

Hydropower is a renewable, non-polluting and environmentally benign source of energy. Hydropower is based on simple concepts. Moving water turns a turbine, the turbine spins a generator, and electricity is produced. it was only at the beginning of the 19th Century with the invention of the hydro turbines that the use of hydropower got popularized. Small-scale hydropower was the most common way of electricity generating in the early $20^{\text {th }}$ century. The first commercial use of hydroelectric power to produce electricity was a waterwheel on the Fox River in Wisconsin in 1882 that supplied power for lighting to two paper mills and a house. by 1924 Switzerland had nearly 7000 small scale hydropower stations in use. In India though, hydro projects up to 25 MW station capacities have been categorized as Small Hydro Power (SHP) projects. The Ministry of New and Renewable Energy, Government of India is the agency responsible for planning, financing and installation of SHP up to 25 MW capacities Further classification for small hydro power in India is as under:

Table 1 Classification of Hydro Power Plant in India

\begin{tabular}{|l|l|}
\hline Type & Capacity (kW) \\
\hline Large- hydro & Up to 100 \\
\hline Small-hydro & 101 to 2000 \\
\hline Mini-hydro & 2001 to 25000 \\
\hline Micro-hydro & $>25001$ \\
\hline
\end{tabular}

Power generation from water depends upon a combination of head and flow. Both must be available to produce electricity. Water is diverted from a stream into a pipeline, where it is directed downhill and through the turbine (flow). The vertical drop (head) creates pressure at the bottom end of the pipeline. The pressurized water emerging from the end of the pipe creates the force that drives the turbine. The turbine in turn drives the generator where electrical power is produced. More flow or more head produces more electricity. Electrical power output will always be slightly less than water power input due to turbine and system inefficiencies.

Water pressure or Head is created by the difference in elevation between the water intake and the turbine. Head can be expressed as vertical distance (feet or meters), or as pressure, such as pounds per square inch (psi). Net head is the pressure available at the turbine when water is flowing, which will always be less than the pressure when the water flow is turned off (static head), due to the friction between the water and the pipe. Pipeline diameter also has an effect on net head.

\section{Turbines}

Turbine is the main piece of equipment in the MHP scheme that converts energy of the falling water into the rotating shaft power. The selection of the most suitable turbine for any particular hydro site depends mainly on two of the site characteristics - head and flow available.

The design speed of a turbine is largely determined by the head under which it operates. Turbines can be classified as high head, medium head or low head machines. They are also typified by the operating principle and can be either impulse or reaction turbines. The basic turbine classification is given in the table below: 
Table 2 Turbine Classification for Different Head

\begin{tabular}{|c|c|c|c|}
\hline & High Head & Medium Head & Low Head \\
\hline Impulse turbines & $\begin{array}{l}\text { Pelton } \\
\text { Turgo }\end{array}$ & $\begin{array}{l}\text { Cross-flow } \\
\text { Multi-jet Pelton } \\
\text { Turgo }\end{array}$ & Cross-flow \\
\hline Reaction turbines & & Francis & $\begin{array}{l}\text { Propeller } \\
\text { Kaplan }\end{array}$ \\
\hline
\end{tabular}

\section{Study Area}

For this research, the study area is considered from the downstream of Wanakbori weir up to Khanpur gauge station, in the lower Mahi River Basin. The study area has been selected mainly because it gets flooded frequently during heavy rains. Hence, it is required to estimate the runoff from the basin including estimation of water levels \& discharge at key locations in the lower Mahi river reach.

The Wanakbori weir on the river Mahi at Wanakbori was constructed as a pickup weir. It is masonry gravity structure about 800 meters long of which the over-flow section is $670 \mathrm{~m}$. The weir is founded on a hard rock formation. The maximum height of the weir above the river bed is 20.6 meter with top R.L. $67.23 \mathrm{~m}$. The design flood discharge over the weir is $47,006 \mathrm{~m}^{3} / \mathrm{sec}$.

\section{Methodology}

The essential data requirements for the development of the flood forecasting model are as follows:

- River Cross Section Data

- Release Data of Wanakbori Weir

- Rainfall Data

- Khanpur Gauge Data

\subsection{River Cross Section Data:}

The most important data for the study was the cross sections of the Lower Mahi River. The cross sections are obtained from Google Earth Imagery. The study reach of the river is $68.21 \mathrm{~km}$ and 70 numbers of river cross sections are considered at the key locations.

\subsection{Release Data:}

For the development of Flood Forecasting model only the area below the Wanakbori Weir is considered. The other essential data obtained for the study is given in Table 3.

Table 3 Data Collection

\begin{tabular}{|l|c|l|}
\hline Type of Data & Duration (From - To) & Source \\
\hline Release Data of Wanakbori Weir & $1990-2013$ & Mahi Irrigation circle office, Nadiad \\
\hline Water Levels at Khanpur Gauging Site & $1990-2013$ & India-WRIS website \\
\hline
\end{tabular}

\subsection{Rainfall Data:}

The Rainfall data required for the study are obtained for the Rain Gauge Stations which are located in the Lower Mahi Basin. The details are given in Table 4.

Table 4 Data of Rain Gauge Station

\begin{tabular}{|l|l|l|l|l|}
\hline \multicolumn{1}{|c|}{ Station Name } & Latitudes & \multicolumn{1}{|c|}{ Longitudes } & Duration (From - To) & Source \\
\hline PILOL & $22^{\circ} 24^{\prime} 39^{\prime \prime}$ & $22^{\circ} 24^{\prime} 39^{\prime \prime}$ & $1990-2013$ & State Water \\
SANSOLI & $22^{\circ} 24^{\prime} 39^{\prime \prime}$ & $22^{\circ} 24^{\prime} 39^{\prime \prime}$ & $1990-2013$ & Data \\
Center, \\
SAVLI & $22^{\circ} 24^{\prime} 39^{\prime \prime}$ & $22^{\circ} 24^{\prime} 39^{\prime \prime}$ & $1990-2013$ & (SWDC), \\
\cline { 1 - 3 } WANAK BORI & $22^{\circ} 24^{\prime} 39^{\prime \prime}$ & $22^{\circ} 24^{\prime} 39^{\prime \prime}$ & $1990-2013$ & Gandhinagar \\
\hline KALOL & $22^{\circ} 24^{\prime} 39^{\prime \prime}$ & $22^{\circ} 24^{\prime} 39^{\prime \prime}$ & $1990-2013$ & \\
\hline
\end{tabular}

HAC-RAS software is used for steady flow, unsteady flow (1-Dimension, 2- Dimension), sedimentation computation, water quality analysis. All above data was put in the software and simulation of the software model was done.

\section{Analysis}

For micro hydro power assessment take flood year 1991. Out of 70 cross section we take three cross section $(10,21,56)$, where micro hydro power plant feasible. Location of cross section no. 10, 21, 56 below: 


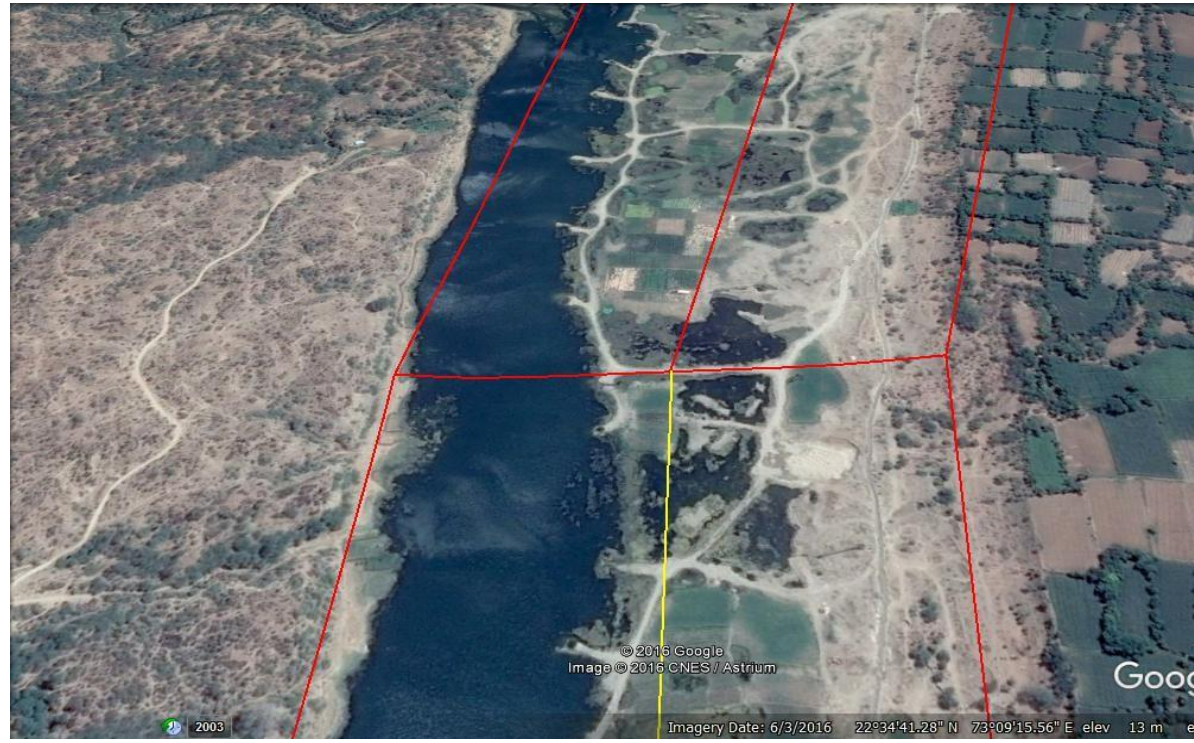

Figure 1 Cross Section No. 10

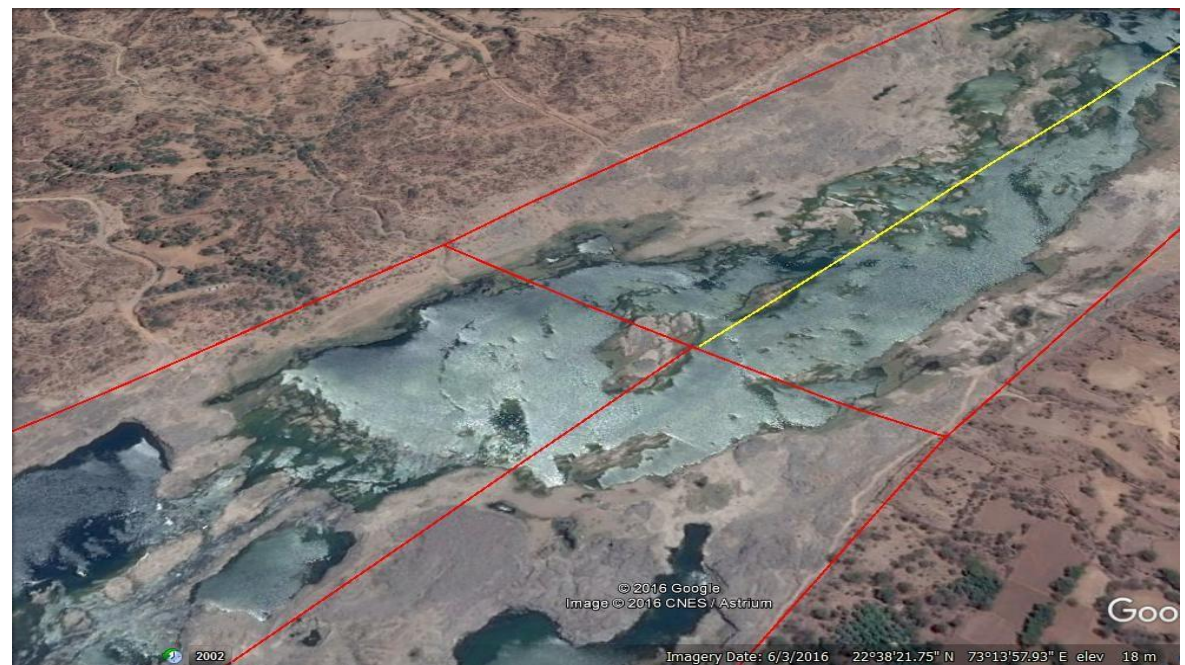

Figure 2 Cross Section No.21

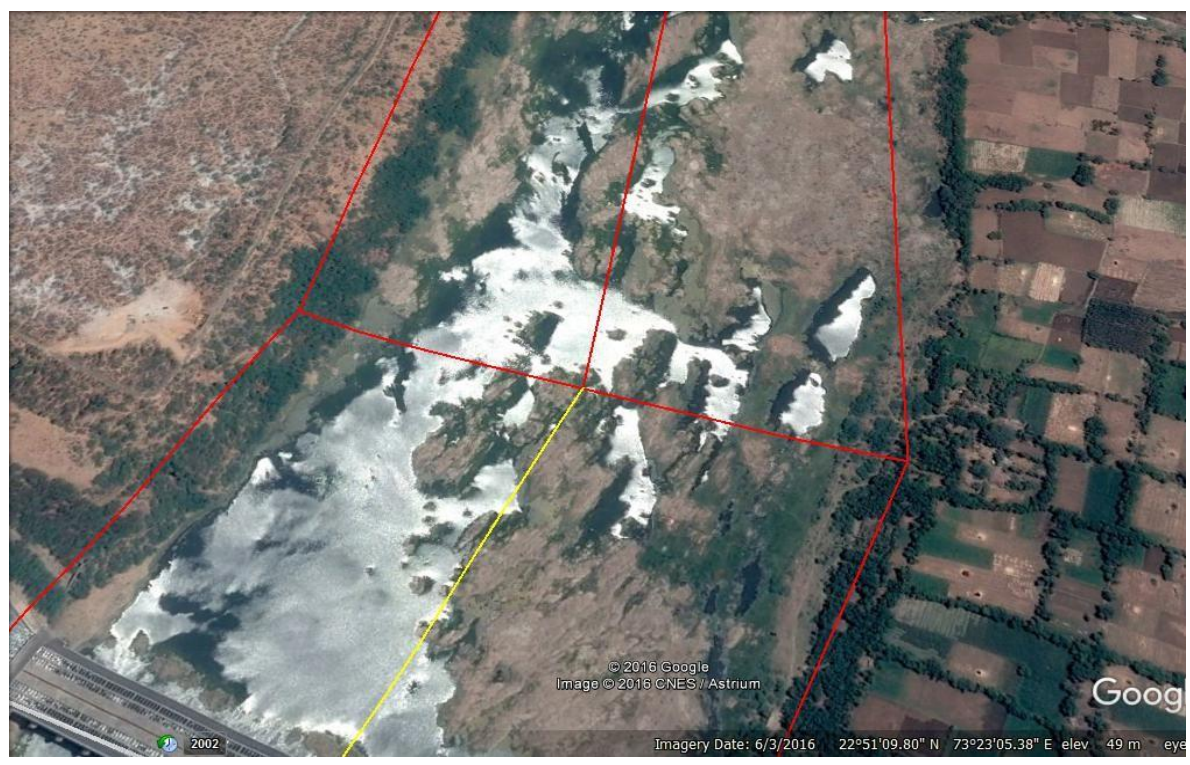

Figure 3 Cross Section No.56 
For, hypothetical micro hydro power analysis done for flood year 1991. Calculate power generation form $P=Q \times H \times e \times 9.81$ Kilowatts $(\mathrm{kW})$. Calculation for Maximum flow and normal flow shown in Table 5.

Table 5 Power Generated Due to Flow for Year 1991

\begin{tabular}{|c|c|c|c|c|c|c|}
\hline \multirow[t]{3}{*}{ Year 1991} & \multirow{2}{*}{\multicolumn{2}{|c|}{56}} & \multicolumn{2}{|c|}{ Cross Section } & \multirow{2}{*}{\multicolumn{2}{|c|}{10}} \\
\hline & & & \multicolumn{2}{|l|}{21} & & \\
\hline & Max flow & Normal & Max flow & Normal & Max flow & Normal \\
\hline Discharge $\left(\mathrm{m}^{3} / \mathrm{s}\right)$ & 11678.41 & 1884.81 & 10076.88 & 1571.73 & 9639.27 & 1521.67 \\
\hline Channel height (m) & 9.96 & 4.97 & 9.96 & 4.1 & 13.77 & 8.86 \\
\hline Power (kWh) & 47544.56 & 3828.968 & 41024.49 & 2634.023 & 54254.51 & 5510.766 \\
\hline
\end{tabular}

\section{Conclusion}

For future requirement for electricity near lower Mahi basin this result might important for suitable site for micro hydro power plant. According to results cross section 56,21,10 all three section most suitable for micro hydro power plant. Cross section no.10 nearby villages Shilli, Khorwad, Pratappura, Poicha, Mevallapura. Cross section no.21 nearby villages Jorapura, Amarapura, Ajabpura. Cross Section no.56 nearby villages Sangol, Kabaria, Juni Dhari and also near at narmada canal. Form the analysis of discharge and water head we use impulse turbine(cross flow, multi jet pelton).This plant also helpful for irrigation, residential, commercial purposes. This kind of plant help reduce non-renewable source use in power plants. Further research can be carried out for designing the suitable Micro Hydro powerplant at the given locations.

\section{References}

[1]. Dilip Singh "MICRO HYDRO POWER" Asian and Pacific Centre for Transfer of Technology of the United Nations - Economic and Social Commission for Asia and the Pacific (ESCAP)

[2]. WECS/UNDP, 1994, A Study on Improvement of Economic Viability of Micro Hydro Plants, Volume 1 (Main report), Water and Energy Commission Secretariat/UNDP, Kathmandu.

[3]. WECS, 1995, Perspective Energy Plan, Supporting Document No. 3, Alternative Energy Technology: An Overview and Assessment, Kathmandu.

[4]. ICIMOD, 1993, Study of Stand-alone Electrification Units, Kathmandu.

[5]. Harry J.R. Driscoll "Micro-hydro power in Dorset: A re-assessment of potential installed capacity" Earth \& E-nvironment 3:52-114.

[6]. Bhagat N. K.(2016) Rainfall - Runoff Co-Relationship for Lower Mahi Basin, India. " PARIPEX - INDIAN JOURNAL OF RESEARCH", Volume : 5, Issue : 12, December-2016 